\title{
Tingkat Kesukaan Parasit pada Ikan Mas (Cyprinus carpio.L) yang Dipelihara dalam Wadah Jaring Apung \\ di Desa Eris, Kabupaten Minahasa, Provinsi Sulawesi Utara \\ (The parasites preference on carp (Cyprinus carpio.L) cultivated in fish farming cage in the Eris Village, Minahasa District, North Sulawesi Province)
}

\author{
Marina F.O. Singkoh ${ }^{1) *}$ \\ 1) Jurusan Biologi Fakultas MIPA Universitas Sam Ratulangi Manado \\ E-mail korespondensi:marinagosal@yahoo.com
}

Diterima 15 Mei 2012, diterima untuk dipublikasikan 1 Agustus 2012

\begin{abstract}
Abstrak
Masyarakat yang berada di sekitar Danau Tondano telah memanfaatkan danau untuk usaha budidaya ikan yang dipelihara dalam wadah jaring apung. Namun usaha ini seringkali dihadapkan oleh adanya serangan penyakit yang disebabkan oleh parasit. Penelitian ini dilakukan dengan tujuan untuk menentukan tingkat kesukaan parasit pada ikan mas. Sampel ikan mas diambil dari usaha budidaya jaring apung di Desa Eris sebanyak 50 ekor. Ikan sampel diambil pada 3 titik pengambilan pada 10 jaring apung milik 10 petani ikan yang berbeda. Tingkat kesukaan diukur/ditentukan berdasarkan tingkat keberadaan jenis parasit pada organ tertentu. Untuk mengetahui tingkat kesukaan tiap spesies parasit pada bagian-bagian tubuh ikan yang diamati dianalisis dengan menggunakan Chi-kuadrat. Parasit yang ditemukan ialah Trichodina sp, Dactylogyrus sp. Gyrodactylus sp, Myxobulus toyamai, Lernea spp, dan spesies $R$ dan parasit dari kelas Cestoidea. Jenis-jenis parasit yang ditemukan lebih menyukai bagian eksternal tubuh ikan dibandingkan bagian internal.

Kata kunci : Cyprinus carpio, Danau Tondano, jaring apung, parasit
\end{abstract}

\begin{abstract}
People residing around Lake Tondano has used the lake for fish farming cages kept in a container. However, these efforts are often confronted by the presence of invasive disease caused by a parasite. The research was conducted to determine the level of preference parasitic on carp. Samples were taken from the carp farming cages in the village of Eris as many as 50 individuals. Fish samples were taken at 3 points decision in 10 cages owned by 10 farmers of different fish. Level of preference measured / determined by the level of presence of certain types of parasites in the organ. To determine the level of preference of each species of parasite in the body parts of fish observed were analyzed using Chi-square. Parasites are found is Trichodina sp, Dactylogyrus sp. Gyrodactylus sp, Myxobulus toyamai, Lernea spp, and species of parasitic $R$ and Cestoidea class. The types of parasites were found to prefer the external parts of the fish compared to the internal parts.

Keywords: Cyprinus carpio, floating net, Lake Tondano, parasites
\end{abstract}




\section{PENDAHULUAN}

Di Indonesia ikan mas (Cyprinus carpio) dipelihara sejak tahun 1810 (Haan 1957 dalam Ardiwinata 1972), sedangkan introduksi ikan mas dari pulau Jawa ke Manado dan Minahasa terjadi pada tahun 1905, (Schuster 1959 dalam Effendi 1975). Ikan mas (C. carpio.L) merupakan salah satu jenis ikan yang mempunyai kemampuan beradaptasi cukup tinggi terhadap lingkungan (Diani 1955). Dikalangan petani maupun masyarakat, ikan mas telah lama dikenal dan disukai (dikonsumsi) sehingga pemasarannya tidaklah sulit dan mempunyai nilai ekonomis penting sebagai ikan komersial.

Masalah penyakit sangat penting karena dapat merugikan usaha perikanan seperti kematian total, penurunan produksi dan penurunan kualitas ikan (Diani 1955). Penyakit ikan adalah segala sesuatu yang dapat menimbulkan gangguan pada ikan, baik secara langsung maupun tidak langsung (Sachlan 1972 dalam Afrianto dan Liviawaty 1992). Penyakit ikan tidak timbul sebagai kejadian mandiri tanpa adanya dukungan dari faktor lain tetapi merupakan hasil interaksi anatara jasad penyebab penyakit itu sendiri dan kondisi lingkungan hidupnya. Interaksi yang tidak serasi ini menyebabkan stress pada ikan, sehingga mekanisme pertahanan diri yang dimilikinya menjadi lemah dan akhirnya mudah diserang oleh penyakit (Afrianto dan Liviawaty 1992). Selain itu makanan yang tidak mencukupi kebutuhan nutrisi baik dalam jumlah maupun mutunya serta kondisi lingkungan yang buruk dapat menyebabkan munculnya penyakit. Secara aktual, masalah terbesar yang sering menyebabkan kerugian ialah serangan parasit pada ikan yang dibudidayakan. Penyakit dapat merugikan usaha budidaya ikan karena secara potensial dapat menurunkan produksi dan kualitas ikan (Yurisman 1994). Hasil penelitian Mangeber (1999) menunjukan bahwa tingkat insidensi parasit pada populasi ikan nila di Desa Eris mencapai $82 \%$. Semuanya ini akan mengurangi nilai dan penerimaan konsumen serta kelayakan ikan untuk dikonsumsi. Jenis ikan yang di Danau Tondano diantaranya ikan nila dan ikan mas. Namun dalam usaha budidaya ini seringkali diperhadapkan oleh adanya serangan penyakit yang bersifat parasit. Informasi yang diperoleh dari beberapa petani ikan ternyata yang paling mudah terserang penyakit adalah ikan nila. Sedangkan ikan mas dikatakan lebih tahan dibandingkan dengan ikan nila. Tapi kemungkinan ikan mas terserang penyakit/parasit tetap ada bahkan bisa sampai menimbulkan kematian pada ikan mas yang dipelihara. Hal ini mungkin karena ikan-ikan tersebut dipelihara pada areal perairan yang sama dan wadah jaring apung untuk setiap jenis ikan letaknya saling berdekatan.

Melihat dampak negatif serangan parasit terhadap ikan maka perlu diadakan penanganan secara tepat dan efektif. Oleh karenanya penelitian terhadap penyakit yang bersifat parasit merupakan hal yang sangat penting untuk dilaksanakan. Penelitian ini bertujuan untuk menentukan tingkat kesukaan parasit pada ikan mas. Di samping itu penelitian ini nantinya dapat memberikan masukan yang berguna bagi pengembangan ilmu pengetahuan pada umumnya dan ilmu perikanan pada khususnya sehingga kualitas budidaya ikan mas terus mengalami peningkatan baik dalam jumlah produksi, bebas penyakit dan memiliki nilai gizi tinggi. 


\section{METODE}

Sampel ikan mas diambil dari usaha budidaya jaring apung di Desa Eris sebanyak 50 ekor. Ikan sampel diambil pada 3 titik pengambilan pada 10 jaring apung milik 10 petani ikan yang berbeda. Ikan diambil secara acak dengan ukuran relatif seragam (18-24 cm), dengan asumsi bahwa jumlah tersebut telah mewakili populasi ikan mas dalam usaha budidaya tersebut. Dalam penelitian ini dilakukan juga pengukuran parameter kualitas air yaitu suhu dan $\mathrm{pH}$ dengan menggunakan refraktometer.

Segera setelah sampel diambil, dilakukan pengamatan di lapangan terhadap keberadaan parasit. Organ atau bagian tubuh yang diamati meliputi sirip, sisik dan insang. Parasit yang ditemukan segera diambil dengan menggunakan pinset kemudian dimasukkan ke dalam wadah yang telah berisi larutan AFA (alcohol formalin acetic acid) dan diberi label. Komposisi larutan AFA ialah $30 \mathrm{ml}$ formalin $40 \%, 250 \mathrm{ml}$ etil alkohol 95\%, $20 \mathrm{ml}$ asam asetat dan $200 \mathrm{ml}$ akuades (Pritchard dan Kause 1982). Setelah dilakukan pengamatan secara eksternal sampel ikan tersebut dimasukkan ke dalam kantong plastik yang telah diisi air, kemudian dibawa ke Laboratorium Patologi Ikan Fakultas Perikanan dan IImu Kelautan Universitas Sam Ratulangi. Sampel ikan yang diambil dalam keadaan hidup dengan kondisi tubuh yang baik. Sisiknya belum dikerik, insangnya belum dikeluarkan dari tempatnya dan bagian-bagaian tubuh lain dalam keadaan utuh.

Setiap sampel ikan diletakkan pada papan bedah, diukur panjang baku dan dilakukan penimbangan berat sebelum dilakukan pemeriksaan parasit. Kemudian dilakukan pemotongan dan pembedahan bagian-bagian tubuh ikan untuk pemeriksaan parasit. Parasit yang ditemukan pada bagian-bagian tubuh ikan dimasukkan ke dalam botol sampel yang telah diisi larutan AFA agar warna dan bentuk parasit yang diawetkan tidak berubah.

Pemeriksaan parasit pada ikan dibagi atas pemeriksaan ektoparasit dan endoparasit. Cara pemeriksaan parasit dilakukan dengan menggunakan teknik yang dianjurkan oleh Fernando et al. (1972) dan Trimariani et al. (1995).

Pemeriksaan ekotoparasit meliputi mata, mulut, insang, sirip dan sisik. Pemeriksaan mata dilakukan dengan mengeluarkan mata, diuraikan dengan pisau dan pinset, lalu dimasukkan ke dalam cawan petri dan diberi sedikit air sebelum pengamatan. Parasit diamati dengan mikroskop atau lup, dipisahkan menurut jenis dan dihitung jumlahnya. Pemeriksaan mulut dilakukan dengan membuka rongga mulut dengan pinset, lalu diamati dengan lup. Pemeriksaan parasit pada insang dilakukan dengan cara insang ikan mas dikeluarkan dengan menggunakan gunting dan pinset, kemudian dipindahkan ke cawan Petri. Lembaran-lembaran insang dipisahkan dengan menggunakan pinset. Kemudian diletakkan pada kaca preparat dan setelah itu diamati dengan mikroskop. Pemeriksaan parasit pada sirip punggung, sirip dada, sirip anal dan sirip ekor dilakukan dengan menggunakan lup dan setiap jari-jari sirip dipisahkan dengan pinset. Kemudian bagian-bagian tubuh ini dimasukkan kedalam gelas ukur yang berisi air dan dilakukan pengocokan. Setelah dikocok cairan yang ada didalam gelas ukur tersebut dipindahkan ke cawan petri dan diamati dengan bantuan lup dan mikroskop. Untuk pemeriksaan parasit 
pada sisik/kulit dilakukan dengan cara menyikat permukaan tubuh ikan dengan sikat halus secara perlahanlahan, kemudian sikat tersebut dicelupkan pada air didalam gelas ukur. Cairan dalam gelas tersebut dipindahkan ke kaca preparat dengan menggunakan pipet untuk kemudian diamati keberadaan parasit dengan menggunakan mikroskop. Semua parasit yang ditemukan dipisahkan menurut jenisnya, dihitung dan dimasukkan ke dalam botol sampel yang telah diisi dengan larutan AFA.

Pemeriksaan endoparasit dilakukan pada usus, hati, darah dan daging. Sampel ikan dibedah, lalu bagian tubuh yang akan diperiksa dipisahkan dengan pinset dan dimasukkan ke dalam cawan petri. Pemeriksaan parasit pada usus dan hati dilakukan dengan cara usus dan hati yang masih utuh diletakkan dalam cawan petri dibelah dengan gunting bedah dan kotoran yang ada dalam usus dikerik dengan pisau dan diberi air setelah itu dikocok. Hasil kerikan tadi dipindahkan ke kaca preparat dengan menggunakan pipet, lalu diamati dengan menggunakan mikroskop.

Pemeriksaan parasit pada darah dilakukan melalui smear darah pada kaca preparat. Darah diambil dari sampel ikan yang masih hidup dengan menggunakan alat suntik di bagian caudal vein. Selanjutnya satu tetes darah diletakkan pada kaca preparat kemudian disentuh dengan kaca preparat lain. Setelah itu ditarik atau didorong mengarah ke ujung preparat lainnya. Sudut antara kedua slide saat dilakukan smear 20-40', kemudian diamati dengan mikroskop. Semua parasit yang ditemukan dipisahkan menurut jenisnya, dihitung dan dimasukkan ke dalam botol sampel yang telah diisi dengan larutan AFA.
Cara pemeriksaan parasit pada daging dilakukan dengan cara parasit pada daging dikeluarkan dengan cara memotong tubuh ikan dengan pisau dari bagian punggung hingga ke arah ekor. Bagian daging yang dipotong diambil dan dipisah-pisahkan dengan menggunakan pisau dan pinset, kemudian dimasukkan ke dalam cawan petri dan diberi sedikit air. Pemeriksaan dengan lup dan mikroskop dilakukan untuk melihat adanya parasit. Parasit yang ditemukan diambil dan dimasukkan kedalam botol sampel yang telah diisi dengan larutan AFA.

Selanjutnya dilakukan pengambilan gambar dengan mikroskop yang dilengkapi kamera pada perbesaran $40 \mathrm{x}, 100 \mathrm{x}$, dan $400 \mathrm{x}$.

Tingkat kesukaan diukur dan ditentukan berdasarkan tingkat keberadaan jenis parasit pada organ tertentu. Untuk mengetahui tingkat kesukaan tiap spesies parasit pada bagian-bagian tubuh ikan yang diamati dianalisis dengan menggunakan Chi-kuadrat (Gasperz, 1991) yaitu :

$$
X^{2}=\Sigma \frac{(O-E)^{2}}{E}
$$

dimana, $\mathrm{O}=$ Frekuensi pengamatan, $\mathrm{E}=$ Frekuensi harapan

\section{HASIL DAN PEMBAHASAN}

Penelitian ini berhasil mengidentifikasi 7 jenis parasit yang diperoleh dari berbagai organ ikan. Di antara ketujuh jenis parasit tersebut, yang tergolong ektoparasit ialah Trichodina sp, Dactylogyrus sp. Gyrodactylus sp, Myxobulus toyamai, Lernea spp, dan spesies $\mathrm{R}$. Sedangkan yang tergolong endoparasit adalah jenis parasit dari kelas Cestoidea (Cacing pita). Jenis dan Klasifikasi parasit yang ditemukan 
Tabel 1. Jenis dan klasifikasi parasit yang ditemukan pada ikan mas yang dibudidayakan di Desa Eris Kecamatan Eris

\begin{tabular}{|c|c|c|c|c|c|c|c|}
\hline Kingdom & Animalia & Animalia & Animalia & Animalia & Animalia & Animalia & - \\
\hline $\begin{array}{c}\text { Sub } \\
\text { kingdom }\end{array}$ & Protozoa & Protozoa & Metazoa & Metazoa & Metazoa & Metazoa & - \\
\hline Filum & Ciliophora & Platyhelmintes & Platyhelmintes & Platyhelmintes & Arthropoda & Arthropoda & - \\
\hline $\begin{array}{l}\text { Sub- } \\
\text { Filum }\end{array}$ & - & - & - & - & - & - & - \\
\hline Kelas & Oligohymenophorea & Monogenea & Monogenea & Cestoidea & Crustacea & Myxosporea & - \\
\hline $\begin{array}{l}\text { Sub- } \\
\text { kelas }\end{array}$ & - & Polionchoinea & Polionchoinea & Cestodaria & - & Cestodaria & - \\
\hline Ordo & Petriticida & Gyrodactylidea & Dactylogyridea & - & Copepoda & Myxosporida & - \\
\hline $\begin{array}{l}\text { Sub } \\
\text { Ordo }\end{array}$ & Mobilina & - & - & - & Cyclopoida & - & - \\
\hline Famili & Trichodinidae & Gyrodactylidea & Dactylogyridea & - & Lernaeidae & Myxobilidae & - \\
\hline Genus & Tricodina & Gyrodactylus & Dactylogyrus & - & Lerneae & Myxobulus & - \\
\hline Spesies & Trichodina sp & $\begin{array}{c}\text { Gyrodactylus } \\
\mathrm{sp}\end{array}$ & $\begin{array}{c}\text { Dactylogyrus } \\
\text { sp }\end{array}$ & - & $\begin{array}{l}\text { Lerneae } \\
\text { spp }\end{array}$ & $\begin{array}{l}\text { Myxobulus } \\
\text { toyamai }\end{array}$ & $\begin{array}{c}\text { Spesies } \\
\mathrm{R}\end{array}$ \\
\hline
\end{tabular}

pada ikan mas ditunjukan pada Tabel 1.

Pemeriksaan parasit pada ikan mas meliputi ekstoparasit dan endoparasit. Ektoparasit terdiri dari mulut, mata, insang dan sirip-sirip (punggung, dada, perut, dubur, ekor) serta sisik/kulit. Tapi untuk organ sisik/kulit tidak ditemukan parasit. Untuk endoparasit terdiri dari usus, daging, hati dan darah. Namun parasit hanya ditemukan pada organ usus. Tingkat kesukaan parasit terutama pada organ insang.

Untuk membandingkan tingkat kesukaan parasit terhadap organ tubuh ikan mas digunakan uji chikuadrat $\left(X^{2}\right)$. Analisis yang dilakukan terbatas pada bagian tubuh yang terkontaminasi oleh parasit. Hasil analisis menunjukkan adanya perbedaan tingkat kesukaan jenis parasit terhadap organ tubuh ikan yaitu : $X^{2}$ hit $6828,578>$ X2 tab 16,8. Hal ini menunjukkan bahwa setiap spesis parasit memiliki tingkat kesukaan yang berbeda dalam menempati organ-organ tubuh ikan mas.
Jenis-jenis parasit yang ditemukan lebih menyukai bagian eksternal tubuh ikan dibandingkan bagian internal. Karena bagian eksternal lebih sesuai dan menunjang bagi parasit untuk berkembangbiak dan bertumbuh. Rohde (1982) menyatakan umumnya parasit lebih suka menghuni organ tubuh ikan, jika organ tersebut dapat ditempati, menyediakan ruang dan makanan yang diperlukan untuk pertumbuhan dan perkembangbiakan.

\section{KESIMPULAN}

Tingkat kesukaan parasit setelah dianalisis ternyata menunjukan adanya perbedaan pada bagian organ yang disukai. Organ mulut 0,0014\%, organ mata $0,0007 \%$, organ insang $0,8 \%$, organ sirip $0,033 \%$ dan organ usus $0,04 \%$. Jenis-jenis parasit yang ditemukan ternyata menyukai bagian eksternal (pemeriksaan ektoparasit) tubuh ikan dibandingkan bagian internal (pemeriksaan endoparasit). 
68 JURNAL BIOSLOGOS. AGUSTUS 2012. VOL. 2 NOMOR 2

Tabel 2. Spesies parasit pada bagian tubuh ikan

\begin{tabular}{|c|c|c|c|}
\hline Spesies Parasit & Bagian Tubuh & $\begin{array}{c}\text { Jumlah Individu } \\
\text { (ni) }\end{array}$ & $\begin{array}{l}\text { Total individu Tiap } \\
\text { spesies Parasit }\end{array}$ \\
\hline Dactylogyrus sp & $\begin{array}{l}\text { Mata } \\
\text { Insang } \\
\text { Sirip } \\
\text { Punggung } \\
\text { Sirip Dada } \\
\text { Sirip Perut } \\
\text { Sirip Dubur }\end{array}$ & $\begin{array}{c}1 \\
566 \\
3 \\
3 \\
8 \\
3\end{array}$ & 584 \\
\hline Trichodina & $\begin{array}{l}\text { Insang } \\
\text { Sirip } \\
\text { Punggung } \\
\text { Sirip Dada } \\
\text { Sirip Perut } \\
\text { Sirip Dubur } \\
\text { Sirip Ekor }\end{array}$ & $\begin{array}{c}151 \\
26 \\
33 \\
81 \\
33 \\
7\end{array}$ & 331 \\
\hline Gyrodactylus sp & $\begin{array}{l}\text { Mulut } \\
\text { Insang } \\
\text { Sirip } \\
\text { Punggung } \\
\text { Sirip Dada } \\
\text { Sirip Perut } \\
\text { Sirip Dubur } \\
\text { Sirip Ekor }\end{array}$ & $\begin{array}{c}2 \\
270 \\
6 \\
11 \\
4 \\
2 \\
1\end{array}$ & 296 \\
\hline $\begin{array}{l}\text { Myxobulus } \\
\text { toyamai }\end{array}$ & Insang & 136 & 136 \\
\hline Cacing & Usus & 57 & 57 \\
\hline Lerneae spp & Insang & 6 & 6 \\
\hline Spesies R & Sirip Perut & 1 & 1 \\
\hline
\end{tabular}


DAFTAR PUSTAKA

Afrianto E, Liviawaty E (1992) Pengendalian hama dan penyakit ikan. Kanisius, Yogyakarta

Daelami D (2007) Agar Ikan Sehat. Penebar Swadaya, Jakarta

Effendie MI (1975) Biologi perikanan. Studi natural histori. Fakultas Perikanan IPB, Bogor

Fernando $\mathrm{CH}$, Furtado JL, Gussev AV, Hanek G, Kakonge SA (1972) Methods for study of freswater fish parasites. University of Watelou

Gasperz V (1991) Metode perancangan percobaan. Armico, Jakarta

Grabda J (1991) Marine fish patology. PWN-Polish Scientific Publisher, Warszawa

Noble ER, Noble GA (1989) Parasitology. Lea and Febiger Inc. Philadelphia, USA

Odum HT (1983) Ekologi Sistem. Gadjah Mada University Press, Yogyakarta

Prichard MH, Kause (1982) The Collection and preservation of animal parasites. University of Nebrasca Press, London.
Post G (1987) The Fish health. T. F. H Publication Inc. For Revised and Expended Edition. New Jersey. pp 81-209

Rohde K (1982) Ecology of marine parasites. University of Queensland Press, New York

Saanin H (1968) Taksonomi dan kuntji idenfikasi ikan. Jilid I dan II. Binatjipta, Bandung

Suryani (2006) Budidaya ikan air tawar. PT. Citra Adi Parama,Yogyakarta

Trimariani A, Sarono A, Taib WN, Hariyanto S, Novianti W, Wardhani S, Setiyaningsih (1995) Petunjuk teknis perlakuan dan pencegahan penyakit ikan golongan parasit dan jamur. Pusat Karantina Pertanian dan Fakultas Pertanian Jurusan Perikanan, Universitas Padjajaran, Bandung

Yurisman, Erlambang T (1994) Ectoparasites in the fingerling fish collected ponds Tangkerang PekanBaru. Himpunan Alumni Fakultas Perikanan Universitas Riau, Terubuk. pp.21-30 